\title{
BMJ Open Formative peer assessment in healthcare education programmes: protocol for a scoping review
}

\author{
Marie Stenberg, Elisabeth Mangrio, Mariette Bengtsson, Elisabeth Carlson
}

To cite: Stenberg M, Mangrio E, Bengtsson M, et al. Formative peer assessment in healthcare education programmes: protocol for a scoping review. BMJ Open 2018;8:e025055. doi:10.1136/ bmjopen-2018-025055

- Prepublication history for this paper is available online. To view these files please visit the journal online (http://dx.doi. org/10.1136/bmjopen-2018025055).

Received 27 June 2018 Revised 17 August 2018 Accepted 8 October 2018

Check for updates

(C) Author(s) (or their employer(s)) 2018. Re-use permitted under CC BY-NC. No commercial re-use. See rights and permissions. Published by BMJ.

Department of Care Science, Faculty of Health and Society, Malmö University, Malmo, Sweden

Correspondence to

Marie Stenberg;

marie.stenberg@mau.se

\section{ABSTRACT}

Introduction In formative peer assessment, the students give and receive feedback from each other and expand their knowledge in a social context of interaction and collaboration. The ability to collaborate and communicate are essential parts of the healthcare professionals' competence and delivery of safe patient care. Thereby, it is of utmost importance to support students with activities fostering these competences during their healthcare education. The aim of the scoping review is to compile research on peer assessment presented in healthcare education programmes, focusing formative assessment. The result of the scoping review will form the basis for developing and conducting an intervention focusing collaborative learning and peer assessment in a healthcare education programme.

Methods and analysis The scoping review will be conducted by using the framework presented by Arksey \& 0 'Malley and Levac et al. The primary research question is: How are formative peer assessment interventions delivered in healthcare education? The literature search will be conducted in the peer-reviewed databases PubMed, Cumulative Index to Nursing and Allied Health Literature, Education Research Complete and Education Research Centre between September and December 2018. Additional search will be performed in Google Scholar, hand-searching of reference lists of included studies and Libsearch for identification of grey literature. Two researchers will independently screen title and abstract. Full-text articles will be screened by three researchers using a charting form. Studies meeting the inclusion criteria will be critically evaluated using the Critical Appraisal Skills Programme. A flow diagram will present the included and excluded studies. A narrative synthesis will be conducted by using thematic analysis as presented by Braun and Clarke. The findings will be presented under thematic headings using a summary table. To enhance validity, stakeholders from healthcare education programmes and healthcare institutions will be provided with an overview of the preliminary results.

Ethics and dissemination Research ethics approval is not required for the scoping review.

\section{INTRODUCTION}

Peer assessment is described as an essential part of collaborative learning since students exercise their ability to give and receive feedback. ${ }^{1}$ This supports students in gaining

\section{Strength and limitations of this study}

The result of the scoping review will establish a baseline for understanding the concept of formative peer assessment in healthcare education programmes prior to developing an intervention focusing peer assessment in a healthcare education programme.

- A systematic search strategy will be conducted in four electronic databases with peer-reviewed literature, including search in library databases for inclusion of books, e-books and grey literature.

- Search strategies will be developed in collaboration with a research librarian well versed using research databases.

- No formal quality assessment will be conducted as the scoping review aims to provide a map of the landscape of formative peer assessment in healthcare education.

- Only articles and documents published in English will be included.

insights and understanding of assessment criteria and their personal approach to an assessment task mirrored in a peer. ${ }^{1}$ Furthermore, peer assessment helps students to develop judgement skills, critiquing abilities and self-awareness. ${ }^{1}$ It can be defined as 'an arrangement in which individuals consider the amount, level, quality, or success of the products or outcomes of learning of peers of similar status' (Topping and Ehly, p118). ${ }^{2}$ Peer assessment has been described in a variety of contexts and with various aims including measuring professional competence of medical students, ${ }^{3}$ as a strategy to enhance students' engagement in their own learning, ${ }^{45}$ and development of employability skills for students in higher education. ${ }^{6}$

In a peer-assessment activity, students take responsibility for assessing the work of their peers against set assessment criteria, ${ }^{1}$ and can be conducted as summative or formative assessments. The purpose of summative assessment is the grading and evaluation of students' learning. ${ }^{7}$ On the other hand, 
formative assessment focus the development of students' learning processes. $^{8}$ In formative peer assessment, the intention is to help students help each other when planning their learning. ${ }^{9}$ The students expand their knowledge in a social context of interaction and collaboration according to social constructivism principles. ${ }^{10}{ }^{11}$ In this social context, they identify their strengths and weaknesses and develop metacognitive, personal and professional skills. ${ }^{9}$ It is conversational in nature ${ }^{12}$ and fundamental is the use of feedback. Feedback is an integral aspect of peer assessment ${ }^{7}$ with the intention to enhance student learning. ${ }^{13}$

A recent published review of assessment in higher education $^{14}$ raised the issue that studies on peer assessment are deficient in referring to exactly what peer assessment aims to achieve and in addition empirical investigations are missing. Boud et al highlighted the importance of a shift in assessment, from individualistic assessment approaches to peer assessment if collaboration such as manifested in collaborative learning models is to be fostered. The ability to collaborate, communicate, assess, give and receive feedback are essential parts of healthcare professionals' competence and delivery of safe patient care. Thereby, it is of utmost importance to support students with activities fostering those competences during their healthcare education. These competences are related to professional teamwork, as well as broader goals for lifelong learning, and as argued by Boud $e t \mathrm{al}^{\mathrm{l}}$ address course-specific goals not readily developed otherwise. Therefore, the scoping review of peer assessment in higher education will act as an important guide prior to develop an empirical investigation focusing peer assessment interventions in a healthcare education programme.

\section{METHOD}

A scoping review aims to map the concepts, main sources and evidence available in a particular research area to get a broader understanding of a specific subject ${ }^{15}$ and has increased in popularity in recent years in health and social sciences. ${ }^{16}$ Scoping reviews are often conducted as a preliminary investigative process that help the researchers to formulate a research question and develop research proposals ${ }^{17}$ and as essential basis for curriculum development and programme implementation. ${ }^{18}$

This scoping review will be conducted by using the York methodology by Arksey and O'Malley ${ }^{15}$ and taking into consideration recommendations presented by Levac et $a l .{ }^{19}$ A scoping review follows a six-stage process including: (1) identifying a research question; (2) identifying relevant studies; (3) study selection; (4) charting the data; (5) collating, summarising and reporting the result; and (6) consultation..$^{1519}$ This six-stage process associates with the process in conducting a systematic review. They both use rigorous and transparent methods to identify and analyse all the relevant literature pertaining to a research question. ${ }^{20}$ This scoping review does not aim to assess the quality and validity of the studies in order to synthesise best practice guidelines as in a systematic review. Rather, it aims to get a broad picture and to highlight recent efforts and key concepts of peer assessment as an integral component for students in higher education. Therefore, this scoping review need to include a greater range of methodologies and study designs than what would be possible in a systematic review, that often focus on randomised controlled trials. ${ }^{15}$

Furthermore, a scoping review can be of use when a topic is of a complex or heterogeneous nature ${ }^{21}$ and as an essential basis for curriculum development and programme implementation. ${ }^{18}$ Since the literature on peer assessment is extensive and with some ambiguity in precise definitions ${ }^{14}$ and conducted in varying contexts in higher education, this method seemed appropriate to answer the research questions. In other words, peer assessment is multifaceted, and a scoping review may provide the researchers with a broad and in-depth knowledge of this particular subject. The reported result will be essential for conducting further development of an intervention aiming to implement and evaluate peer assessment as part of a collaborative learning approach in a healthcare education programme.

\section{Stage 1: identifying the research question}

The aim of this scoping review is to compile research about peer assessment presented in higher education, focusing formative assessment. The primary research question is:

- How are formative peer assessment interventions delivered in healthcare education?

Further questions to be answered are:

- What are the rationales for using formative peer assessment in healthcare education?

- What experiences of formative peer assessment are presented from the perspective of students and teachers in healthcare education and in what context (eg, clinical practice, preclinical and theoretical courses)?

- What outcomes are presented from formative peer assessment interventions?

Levac et $a l^{19}$ recommend a clear articulation of the research question. In a systematic review, the question to guide the search is often based on the 'Population Intervention Context Outcome' elements. Since a scoping review has less restrictive inclusion criteria than a systematic review, the 'Population Concept and Context' elements (table 1) can be used to establish effective search criteria. ${ }^{22}$

Table 1 The Population Concept and Context mnemonic as recommended by the Joanna Briggs Institute ${ }^{22}$

\begin{tabular}{|c|c|c|}
\hline Population & Concept & Context \\
\hline $\begin{array}{l}\text { Students } \\
\text { assessing } \\
\text { students }\end{array}$ & $\begin{array}{l}\text { Intervention, rationale, } \\
\text { outcome, context and } \\
\text { experience of formative } \\
\text { peer assessment. }\end{array}$ & $\begin{array}{l}\text { Healthcare } \\
\text { education } \\
\text { programmes in } \\
\text { higher education. }\end{array}$ \\
\hline
\end{tabular}




\section{Stage 2: identifying relevant studies}

The literature search will be conducted in the peer-reviewed databases, PubMed, Cumulative Index to Nursing and Allied Health Literature, Education Research Complete and Education Research Centre. Search tools such as Medical Subject Headings, Headings, Thesaurus and Boolean operators (AND/OR) will be used to expand and narrow the search. Additional search will be performed in Google Scholar, hand-search reference lists of included studies and Libsearch for identification of grey literature. The search will be conducted between September and December 2018. No limitations will be set to the year of publication. Finally, search strategies will be developed in collaboration with a research librarian well versed in research databases.

\section{Inclusion and exclusion criteria}

The following inclusion criteria will be applied in the search: (a) the articles have to address peer assessment in higher education; (b) focusing formative peer assessment; (c) students in healthcare education programmes; (d) peer reviewed articles, grey literature, books and so on; (e) studies evaluated with moderate or high methodological quality according to the Critical Appraisal Skills Programme (CASP). ${ }^{23}$ Initially, the search terms will be purposefully broad (eg, peer assessment, higher education) in order to capture the range of published literature. However, the extensiveness of material will determine if more narrow inclusion criteria are necessary for managing the material.

Since the distinction between different assessment terms and how different authors define peer assessment varies ${ }^{14}$ similar concepts related to peer assessment, for example, peer feedback and peer evaluation, will be incorporated in the search to ensure that no study is missed due to ambiguity in definition of the subject.

Articles including summative peer assessment will be excluded unless the study involves formative assessment. However, a distinction between the two must be transparent if the study is to be included. If there is any uncertainty, the study will be excluded. Furthermore, full articles, abstracts, conference posters or power point presentations unavailable for review will be excluded.

\section{Stage 3: study selection}

Initially, the title and abstract will be screened by two members of the research team. The team may at this stage need to discuss the inclusion and exclusion criteria and refine the search. ${ }^{19}$ If the title is in line with the review purpose, the abstract will be read. This procedure will be conducted by two researchers separately, guided by the inclusion criteria and research questions. If any disagreement appears, a third research member will be consulted. This initial step will determine whether the criteria capture relevant studies. Further, the full-text articles will be imported into the web-based bibliographic manager RefWorks 2.0 to enable removal of duplicates and for organisational feasibility. Each paper will be given a unique number for identification and to keep track of included and excluded articles. ${ }^{24}$

\section{Stage 4: charting the data}

The full-text articles will be screened by three researchers independently. A charting form will be used for managing the documentation of extracted data from the included studies. The charting form will include the inclusion criteria and an explanation of why the study is included or excluded at this stage in the process. If there are any reservations or discordant opinions a fourth researcher will be consulted until consensus is reached. Studies meeting the inclusion criteria will be critical evaluated using CASP. ${ }^{23}$ The methodological quality will be graded with moderate when meeting 6-8 criteria and high 9-10 criteria of the CASP checklist. ${ }^{25}$ To enable replications by others, increase reliability of the findings and for methodological accuracy ${ }^{15}$ the process will be documented using the Preferred Reporting Items for Systematic Reviews and Meta-Analyses (PRISMA) presented by Moher et al. ${ }^{26}$ The PRISMA flow diagram visualise selection process of included and excluded articles during each stage of the search process. The PRISMA checklist will support rigour report of the review using the 24 item checklist. ${ }^{26}$

\section{Stage 5: collating, summarising and reporting results}

Collating and managing the results from the included articles will be conducted by using a data analysis software program, NVivo V.11. NVivo is a code-based system developed to support structured qualitative data. ${ }^{27}$ Even though, the analysis part of the data material needs to be abstracted by the researcher, the software may support an overview of codes, themes and their relationships and connections. ${ }^{27}$

We will perform a narrative synthesis using an inductive methodology. Analysing the qualitative data will be conducted by using the principles for thematic analysis as presented by Braun and Clarke. ${ }^{28}$ Thematic analysis is a method for identifying, analysing and reporting patterns within data ${ }^{28}$ and has a both qualitative and quantitative methodology. ${ }^{29}$ It allows a large amount of data and can highlight differences and similarities across a data set. The themes will be identified at a semantic level from the written text. ${ }^{28}$ To maintain quality and trustworthiness each stage of the data analysis will be presented in a scheme. ${ }^{28}$ The findings will be presented under thematic headings using a summary table which can inform a description of key points. Further, detailed tables will present: (a) author(s), (b) the geographical distribution of studies, (c) year of publication, (d) educational interventions presented, (e) the professional healthcare programme that the studies refers to, (f) reported experiences, outcome and main findings of peer assessment initiatives and $(\mathrm{g})$ research methodology.

\section{Stage 6: consultation}

Consultation is an optional stage ${ }^{15}$; however, since it adds methodological rigour ${ }^{19}$ it will be incorporated in 
the scoping review. The consultation will be conducted when preliminary results are organised in charts and tables (stage 5). Stakeholders from healthcare education programmes (students and teachers) and healthcare institutions (preceptors) will be provided with an overview of the preliminary results. The purpose of the consultation is to enhance the validity of the study outcome.

\section{ETHICS AND DISSEMINATION}

Information will only be extracted from public databases. The result of this scoping protocol will form the basis for conducting a scoping review of formative peer assessment in a healthcare education programme. The results will be presented at national and international conferences and published in peer-reviewed journals.

Contributors MS led the design, search strategy and conceptualisation of this work and drafted the protocol. EM, MB and EC were involved in the conceptualisation of the review design, inclusion and exclusion criteria and provided feedback on the methodology and the manuscript. All authors give their approval to the publishing of this protocol manuscript.

Funding The authors have not declared a specific grant for this research from any funding agency in the public, commercial or not-for-profit sectors.

Competing interests None declared.

Patient consent Not required.

Ethics approval Research ethics approval is not required for a scoping review.

Provenance and peer review Not commissioned; externally peer reviewed.

Open access This is an open access article distributed in accordance with the Creative Commons Attribution Non Commercial (CC BY-NC 4.0) license, which permits others to distribute, remix, adapt, build upon this work non-commercially, and license their derivative works on different terms, provided the original work is properly cited, appropriate credit is given, any changes made indicated, and the use is non-commercial. See: http://creativecommons.org/licenses/by-nc/4.0/.

\section{REFERENCES}

1. Boud D, Cohen R, Sampson J. Peer learning and assessment. Assessment \& Evaluation in Higher Education 1999;24:413-26.

2. Topping KJ, Ehly SW. Peer assisted learning: a framework for consultation. Journal of Educational and Psychological Consultation 2001;12:113-32.

3. Dannefer EF, Henson LC, Bierer SB, et al. Peer assessment of professional competence. Med Educ 2005;39:713-22.

4. Casey D, Burke E, Houghton C, et al. Use of peer assessment as a student engagement strategy in nurse education. Nurs Health Sci 2011;13:514-20.

5. Orsmond * P, Merry S, Callaghan A. Implementation of a formative assessment model incorporating peer and self-assessment. Innovations in Education and Teaching International 2004;41:273-90.

6. Cassidy S. Developing employability skills: peer assessment in higher education. Education + Training 2006;48:508-17.
7. Black P, Wiliam D. Assessment and classroom learning. Assessment in Education: Principles, Policy \& Practice 1998;5:7-74.

8. Sadler DR. Beyond feedback: developing student capability in complex appraisal. Assessment \& Evaluation in Higher Education 2010;35:535-50.

9. Topping KJ. Peer assessment. Theory Pract 2009;48:20-7.

10. Reece I, Walker S. A practical guide to teaching, training and learning. 6th edn. Sunderland: Business Education Publishers, 2007.

11. Olusegun S. Constructivism learning theory: a paradigm for teaching and learning. Journal of Research \& Method in Education 2015;56:66-70.

12. Hastie C, Fahy K, Parratt J. The development of a rubric for peer assessment of individual teamwork skills in undergraduate midwifery students. Women Birth 2014;27:220-6.

13. Nicol DJ, Macfarlane-Dick D. Formative assessment and selfregulated learning: a model and seven principles of good feedback practice. Studies in Higher Education 2006;31:199-218.

14. Academy HE. et alAssessment and feedback in higher education. A review of literature of Higher Education Academy. In: Jackel B, Pearce J, Radloff A, Daniels E, . eds. Tranforming teaching and inspiring learning, 2017.

15. Arksey H, O'Malley L. Scoping studies: towards a methodological framework. Int J Soc Res Methodol 2005;8:19-32.

16. Pham MT, Rajić A, Greig JD, et al. A scoping review of scoping reviews: advancing the approach and enhancing the consistency. Res Synth Methods 2014;5:371-85.

17. Davis K, Drey N, Gould D. What are scoping studies? A review of the nursing literature. Int J Nurs Stud 2009;46:1386-400.

18. Guerra O, Kurtz D. Building collaboration: a scoping review of cultural competency and safety education and training for healthcare students and professionals in Canada. Teach Learn Med 2017;29:129-42.

19. Levac D, Colquhoun H, O'Brien KK. Scoping studies: advancing the methodology. Implement Sci 2010;5:69.

20. DiCenso A, Martin-Misener R, Bryant-Lukosius D, et al. Advanced practice nursing in Canada: overview of a decision support synthesis. Nurs Leadersh 2010;23:15-34.

21. Mays N, Roberts E, Popay J. et alSynthesizing research evidence. In: Fulop N, Allen P, Clark A, Black N, . eds. Studying the organization and delivery of services: Research methods. London: Routledge, 2001:188-219.

22. Joanna Briggs Institute. The Joanna Briggs Institute Reviewers' Manual 2015. Methodology for JBI Scoping reviews. South Australia The University of Adelaide, 2015.

23. Critical Appraisal Skills Programme. CASP checklist. 2018. https:// casp-uk.net/casp-tools-checklists/ (Accessed 5 Aug 2018).

24. Daudt HM, van Mossel C, Scott SJ. Enhancing the scoping study methodology: a large, inter-professional team's experience with Arksey and O'Malley's framework. BMC Med Res Methodol 2013;13:48

25. Horntvedt MT, Nordsteien A, Fermann T, et al. Strategies for teaching evidence-based practice in nursing education: a thematic literature review. BMC Med Educ 2018;18:172.

26. Moher D, Liberati A, Tetzlaff J, et al. Preferred reporting items for systematic reviews and meta-analyses: the PRISMA statement. PLOS Med 2009;6:e1000097.

27. Silver C, Lewins A. Using software in qualitative research a step-bystep guide. London: Sage Publication, 2007.

28. Braun V, Clarke V. Using thematic analysis in psychology. Qual Res Psychol 2006;3:77-101.

29. Mays N, Pope C, Popay J. Systematically reviewing qualitative and quantitative evidence to inform management and policy-making in the health field. J Health Serv Res Policy 2005;10(Suppl 1):6-20. 